\title{
Systematic Errors Introduced into Sorghum Grain Yield Data: Does the Multiseed ( $m s d$ ) Trait Increase Sorghum Seed Yield?
}

\author{
Dennis C. Gitz III, Jeffrey T. Baker, Zhanguo Xin, John E. Stout, Robert J. Lascano \\ USDA-Agricultural Research Service ${ }^{1}$, Cropping Systems Research Laboratory, Lubbock, TX, USA \\ Email: dennis.gitz@usda.gov
}

How to cite this paper: Gitz III, D.C., Baker, J.T., Xin, Z.G., Stout, J.E. and Lascano, R.J. (2019) Systematic Errors Introduced into Sorghum Grain Yield Data: Does the Multiseed (msd) Trait Increase Sorghum Seed Yield? American Journal of Plant Sciences, 10, 1503-1516.

https://doi.org/10.4236/ajps.2019.109106

Received: August 14, 2019

Accepted: September 6, 2019

Published: September 9, 2019

Copyright ( 2019 by author(s) and Scientific Research Publishing Inc. This work is licensed under the Creative Commons Attribution International License (CC BY 4.0).

http://creativecommons.org/licenses/by/4.0/ (c) (i) Open Access

\begin{abstract}
Multiseed (msd) mutant sorghum [Sorghum bicolor (L.) Moench] lines with greatly increased seed numbers were developed. It was originally thought that the $m s d$ trait could increase grain yield several times in comparison with the wild type from which the mutant was derived. However, in a small plot trial, $m s d$ seed yield decreased when compared to the parent line. Herein we report results that $m s d$ seed yield remained either unchanged or slightly increased in comparison to the parent line. We suggest that attempts to measure msd sorghum seed yield were complicated due to systematic errors associated with the post-harvest processing methods, including threshing and pneumatic winnowing equipment that was used for harvest. That is, seed recovery and seed loss from individual panicles were affected by the post-harvest processing. When evaluating sorghum grain yield of types with different seed sizes, threshing and seed cleaning harvesting methods should be optimized for each sorghum line.
\end{abstract}

\section{Keywords}

Sorghum, Yield, Yield Components, msd, Multiseed, Yield Measurement, Error

\footnotetext{
${ }^{1}$ The U.S. Department of Agriculture (USDA) prohibits discrimination in all its programs and activities on the basis of race, color, national origin, age, disability, and where applicable, sex, marital status, familial status, parental status, religion, sexual orientation, genetic information, political beliefs, reprisal, or because all or part of an individual's income is derived from any public assistance program. (Not all prohibited bases apply to all programs.) Persons with disabilities who require alternative means for communication of program information (Braille, large print, audiotape, etc.) should contact USDA's TARGET Center at (202) 720-2600 (voice and TDD). To file a complaint of discrimination, write to USDA, Director, Office of Civil Rights, 1400 Independence Avenue, S.W., Washington, D.C. 20250-9410, or call (800) 795-3272 (voice) or (202) 720-6382 (TDD). USDA is an equal opportunity provider and employer.
} 


\section{Introduction}

Although grain sorghum does not represent a large share of U.S. agricultural production, it is an important source of human food worldwide. Of the 60 million metric tons of sorghum and 27 MMT of millet produced worldwide, about $50 \%$ of sorghum and $80 \%$ of millet is consumed by humans [1]. North American production contrasts in that it is largely dedicated to animal feed and to ethanol-fuel production, along with supplying niche markets such as molasses, wild bird seed, natural bristle broom manufacturing, and whiskey and vodka production. Other uses for sorghum continue to be developed [2]. Sorghum is an agriculturally important crop in part due to its relative heat and drought tolerance when compared to other species, such as corn. Sorghum grain yield is less sensitive to variable rainfall typical of semiarid environments. So, the lower commercial value of sorghum grain, as compared to corn, for example, is offset by the lower risk associated with more consistent yields. For these reasons early 20th century financial institutions often required the planting of sorghum in addition to other crops as a precondition for loans to producers [3] [4].

As wind-powered irrigation gave way to internal combustion engine-powered irrigation production, the crop yield variability and risk associated with crop failure decreased. Sorghum became less important as growers turned to more profitable crops such as corn. While some sorghum improvement programs continued, breeding efforts became increasingly focused on other crops. This may have led to the observed lack of sorghum yield improvements, at least as compared to corn [5]. But now, as aquifers continue to be mined and become more depleted, the water available for irrigation is becoming scarcer and more expensive to lift from deeper levels. Limited irrigation has become an increasingly inadequate replacement for optimal precipitation. The resulting increased dependence on highly variable precipitation has, once again, led to increased risk. This has led to renewed interest in developing higher-yielding sorghums with higher water use efficiencies.

Genetic diversity is a prerequisite to traditional crop improvement methods. In part, because sorghum is a relatively recently domesticated crop, considerable diversity is available to molecular biologists, geneticists, and breeders. The U. S. sorghum germplasm collection alone has more than 40,000 entries, and many other collections exist [6]. In addition to extensive germplasm collections of diverse cultivars and landraces, novel mutant populations have been generated with unique traits that show promise in increasing sorghum yields. One such mutant library was generated by the USDA-ARS from the elite inbred sorghum cultivar BTx-623 mutagenized with ethyl methanesulfonate. A suite of mutants with potentially useful traits such as erect and thick leaves, brown mid-ribs, multiple tillers, and multiseed panicles were developed [7] [8] [9].

The multispeed msd trait exhibited by lines within the USDA sorghum mutant population was thought to potentially increase sorghum grain yield because it exhibited increased numbers of seeds in each panicle as a result of altered seed developmental patterns [10] [11]. The msd mutant lines have three spikelets ca- 
pable of developing a seed whereas conventional sorghums have only one competent terminal spikelet. The important developmental difference between the parent BTx623 and the $m s d$ lines is that the $m s d$ lateral spikelets do not abort once fertilized [10], so that both the terminal and lateral spikelets produce seeds in the $m s d$ lines. As a result of the altered seed development patterns, there are at least two size classes of seeds from the msd line and they are considerably smaller, about half the mass of those from the parent BTx623 line [12] [13]. It was reasoned that increased numbers of seeds would result in an increased carbon sink and increased grain yield increase. Original reports showed a significant increase in msd yield over than of BTx623. However, subsequent work concluded that the $m s d$ trait resulted in either unchanged or even a decreased grain yield as compared to the parent line [12].

The goal of the work described herein was to examine whether seed size could have indirectly affected the results of the $m s d$ grain yield measurements [12]. It was hypothesized that if seeds were mechanically cleaned using settings optimized for conventional sorghum grain [12], pneumatic threshing might have selected against smaller seeds and introduced a systematic error affecting seed recovery and grain yield.

\section{Methods}

\subsection{Mutant Generation and Selection}

A sorghum mutant library was generated as described elsewhere [8] [14]. Briefly, BTx623 [15] seeds were soaked in aqueous ethyl methane sulfonate with gentle agitation $(60 \mathrm{rpm})$ for $16 \mathrm{~h}$ at $25^{\circ} \mathrm{C}$, rinsed with water and then dried. These were designated as the 1st generation mutant (M1) seeds. The M1 seeds were planted and allowed to develop and self-pollinate by bagging the panicles with paper pollination bags after heading and before anthesis to prevent cross-pollination. Panicles setting seeds were manually harvested, individually threshed, planted as M2 plots, allowed to self-pollinate with bagging, and a single fertile panicle selected as a source of M3 seeds. Each M3 family of seeds was subsequently planted as a single plot for phenotype evaluation and selection. Lines with the multiseed phenotype were identified [10] and backcrossed over several generations with the parent line to ensure the trait was from a single mutation and that seeds were from a stable population.

\subsection{Plant Culture}

Seeds from sorghum isolines BTx623 or from the "multiseed" mutants' line, P12 and P15, were planted in the field into single row plots at the USDA Plant Stress Lab (33 $\left.35^{\circ} 41.13^{\prime \prime N}, 101^{\circ} 53^{\prime} 58.70^{\prime \prime} \mathrm{W}\right)$ in Lubbock, TX on Day of Year (DOY) 165 in the 2017-growing season. The nursery is located on the United States' Southern High Plains and experiences a cool semiarid climate (Köppen-Geiger class $B S k$ ). Environmental conditions during development were recorded by a weather station located $100 \mathrm{~m}$ east of the plots and are freely available [16]. Plots con- 
sisted of a single row with seed planted at a depth of $1.5 \mathrm{~cm}$ into North-South oriented rows on raised beds spaced $1 \mathrm{~m}$ apart at a rate of 20 seeds $/ \mathrm{m}$. The soil at the location is an Amarillo fine sandy loam (fine-loamy, mixed, superactive, thermic Aridic Paleustalfs). After planting the plots were furrow irrigated several times to induce emergence and ensure an even stand. After the plants had reached the five to eight leaf stage plants were irrigated with $5 \mathrm{~mm}$ water from a subsurface drip system on DOY 195. At anthesis, panicles were covered with bags to prevent bird damage [17]. After seeds had matured, the bags covering the panicles were tagged, the panicles manually harvested, and stored until they could be threshed.

\subsection{Seed Threshing and Cleaning}

Seeds were either mechanically threshed and pneumatically cleaned or were manually threshed and cleaned using a combination of both manual and pneumatic techniques. Mechanical threshing and cleaning was done with a toothed cylinder Vogel plot thresher (ALMACO ${ }^{2}$, Nevada, IA, US) with settings as typically used by sorghum workers at the facility [18]. Manual threshing was done by rolling the panicles between the hands until no seeds remained on the panicles. Seeds were then passed through a $5 \mathrm{~mm}$ screen to remove large pieces of trash. Remaining large pieces of trash were individually removed by hand and the resulting mixture of seeds and trash was passed through a cyclonic seed cleaner (Grainman Model 63-115-60-VS, Grain Machinery Mfg. Corp., Miami FL, US). Airflow was adjusted for each isoline until no seeds were found in the collected chaff and trash. As seeds were cleaned the chaff and trash was continually inspected to ensure there were no seeds present before discarding. If a single seed was found in the chaff it was removed to the seed sample. If many seeds were found in the trash, the process was repeated at lower air speeds until the samples were deemed "clean".

\subsection{Analysis of Grain Yield Components}

Seed size was determined by image analysis [13]. A subsample of known volume was taken from seeds collected from a single panicle, arranged on a flatbed scanner, scanned at native optical resolution, and a commercial image analysis program was used to determine the number of seeds in the subsample and the major and minor axis of each seed. The volume of each seed was then calculated as a regular ellipsoid having two minor axes of equal length and a longer major axis. The average seed size of each panicle was calculated as the averaged individual seed volumes in each subsample. The grain yield of each panicle was determined as the volume, mass, and number of seeds. The number of seeds in each panicle was estimated by scaling the number of seeds in the subsample volume to the volume of the entire sample. Yield, expressed as mass, was measured ${ }^{2}$ Mention of trade names or commercial products in this publication is solely for the purpose of providing specific information and does not imply recommendation or endorsement by the U.S. Department of Agriculture. 
directly. The unit of replication was the individual plant and the number of replicates varied between eight and ten.

\subsection{Statistical Analyses and Data Presentation}

Experimental effects on grain yield and seed number in threshed and cleaned samples were assessed by multiway ANOVA (PROC GLM) in SAS (SAS v. 9.2). Means separation between isolines was calculated by using multiway t-test with Bonferroni correction. Means separation between threshing methods was computed by using the Student's t-test, or by the Satterwhite's t-test, where unequal variance was found.

\section{Results}

Mean grain yield (grams/panicle), seed numbers (seeds/panicle) and standard error about the mean for each threshing method and isoline are graphically displayed in Figure 1. Panicles/plant were not calculated since plants with only single

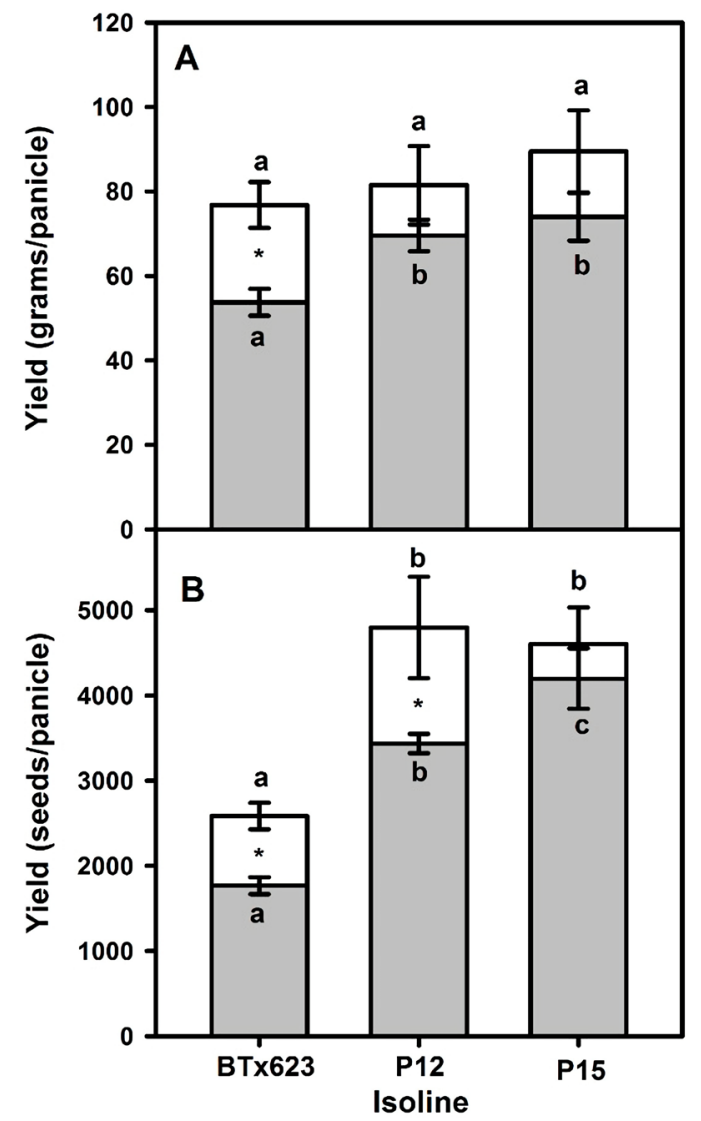

Figure 1. Grain sorghum yield components as (A) grams/panicle, and as (B) Numbers of seeds per panicle of three sorghum isolines. Averages and standard error about mean are shown. Clear bars are results from manual processing and shaded are from mechanical processing. Significance of mean grain yield and seed number differences between isolines and within threshing methods at or below $\mathrm{p}=0.05$ is indicated by different letters. Significant statistical differences $(\mathrm{p}<0.05)$ between threshing methods and within isolines is denoted by asterisks $\left.{ }^{*}\right)$. 
panicles were selected. There was an experiment-wide increase in seed recovery (as seeds captured from each panicle) with manual threshing and cleaning $(\mathrm{p}=$ $0.003)$. There was an experiment wide yield $(\mathrm{p}=0.048)$ and seed number $(\mathrm{p}<$ 0.001 ) responses to isoline across threshing and cleaning methods. A cultivar $\times$ threshing method interaction was found $(p=0.084)$. These were not investigated further.

Results of statistical means separations were also incorporated into Figure 1. Both the P12 and P15 msd isolines exhibited increased mean grain yields as compared to BTx623, but the statistical significance was inconsistent. Measured mean yield increases were significant at the $\mathrm{p}<0.05$ level with machine-threshed samples, but differences were statistically insignificant in hand-threshed samples. When data from both msd isolines were pooled and compared to BTx623 statistically significance grain yield increase was highly significant $(\mathrm{p}<0.001)$. Numbers of seeds were significantly increased in every case by the msd trait. In each and every isoline, seed recovery both as grain yield components, i.e. numbers of seeds and seed mass/panicle, increased with manual hand threshing and cleaning though significance of measured differences was inconsistent.

Graphical representations of seed size distributions are presented in Figure 2. For ease of presentation and of interpretation by the reader the P12 and P15 isoline seed volumes were combined into a single dataset instead of presenting separate isolines. Data were normalized using a simple spreadsheeting software package such that the integrated area under frequency distribution curves was $100 \%$. Curve normalization was used because the numbers of $m s d$ seeds ( $\mathrm{n}=$ 5600 to 5800, hand-threshed and machine-threshed, respectively) was considerably greater than that of the wild type BTx623 ( $\mathrm{n}=1600$ to 1900, hand-threshed and machine-threshed, respectively). Using raw data rather than normalizing resulted in large differences in amplitude of the frequency distribution curve, which though might be of interest in a production setting, obscured differences in the proportion of seed size classes making up the samples (not presented).

To ease comparison between the wild type (WT) and the msd lines, Figure 2 was further divided such that the upper panes (A and B) were from the WT and the lower panes (C and D) were from the mutant lines, left hand panes show the upper and lower $95 \%$ confidence limits about the fitted seed frequency distributions. In both the WT and the msd lines the frequency distribution were broader with manually processed seeds. This was evidenced as a more pronounced shoulder in the WT (Figure 2(A), black lines) and a more complicated broader shape with lower maximal amplitude with the msd lines (Figure 2(C)). Right hand panes depict results of deconvolution of the frequency distribution of seeds, assuming that the measured frequency distribution consists of smaller cohorts of seeds with Gaussian size distributions. The manually and mechanically processed WT seed distribution curves revealed only a small difference in the calculated cohorts of seed sizes detected in the WT (Figure 2(B)). In contrast, hand processing of the msd lines resulted in three cohorts of seeds as 


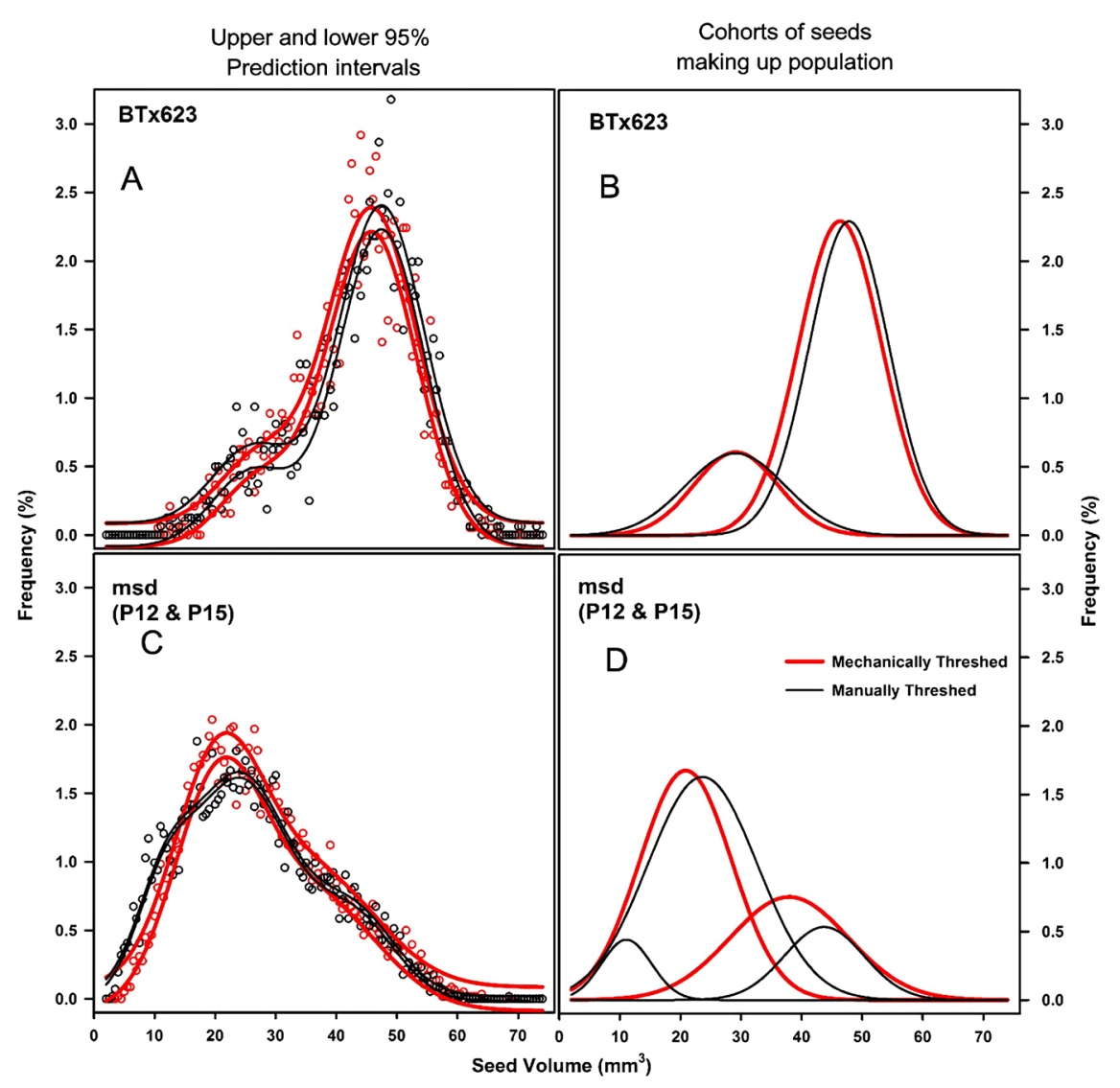

Figure 2. Frequency distribution as a function of seed volume. Left hand panels show results of (A) BTx623 and (C) Combined msd lines. Right hand panels show results of deconvolution of frequency distribution curves of (B) BTx623 and (D) combined msd lines. Red lines and symbols are for mechanically processed seed and black lines and symbols are for manually processed seed.

compared to the two cohorts when mechanically processed (Figure 2(D)). This was also reflected in a larger proportion of seeds having between 2 and $10 \mathrm{~mm}^{3}$ volumes (Figure $2(\mathrm{C})$ ). That is, processing method had little effect on WT seed size distribution, but mechanical processing selected against smaller seeds in the msd lines.

Seed volume, consistency of seed size distributions between processing methods, and threshing efficiency were examined by regression analyses of seed numbers and grain yield per panicle (Figure 3). Grain yield (g/panicle) was plotted as a function of number of seeds/panicle. Thus, the slope of the regression line had units of mass/seed, i.e., g/seed. Differences in slope between processing methods indicates a lack of consistency between the two methods, a selection for different seed sizes. If there were no selection for seed size, that is, if all seeds of all sizes were recovered with equal efficiency in each processing method, then the calculated regression lines would intersect at the origin. So, differences in the intercept indicate seed size selection by processing method. Harvesting efficiency was then indicated by simple correlation coefficients from the regression analysis. 


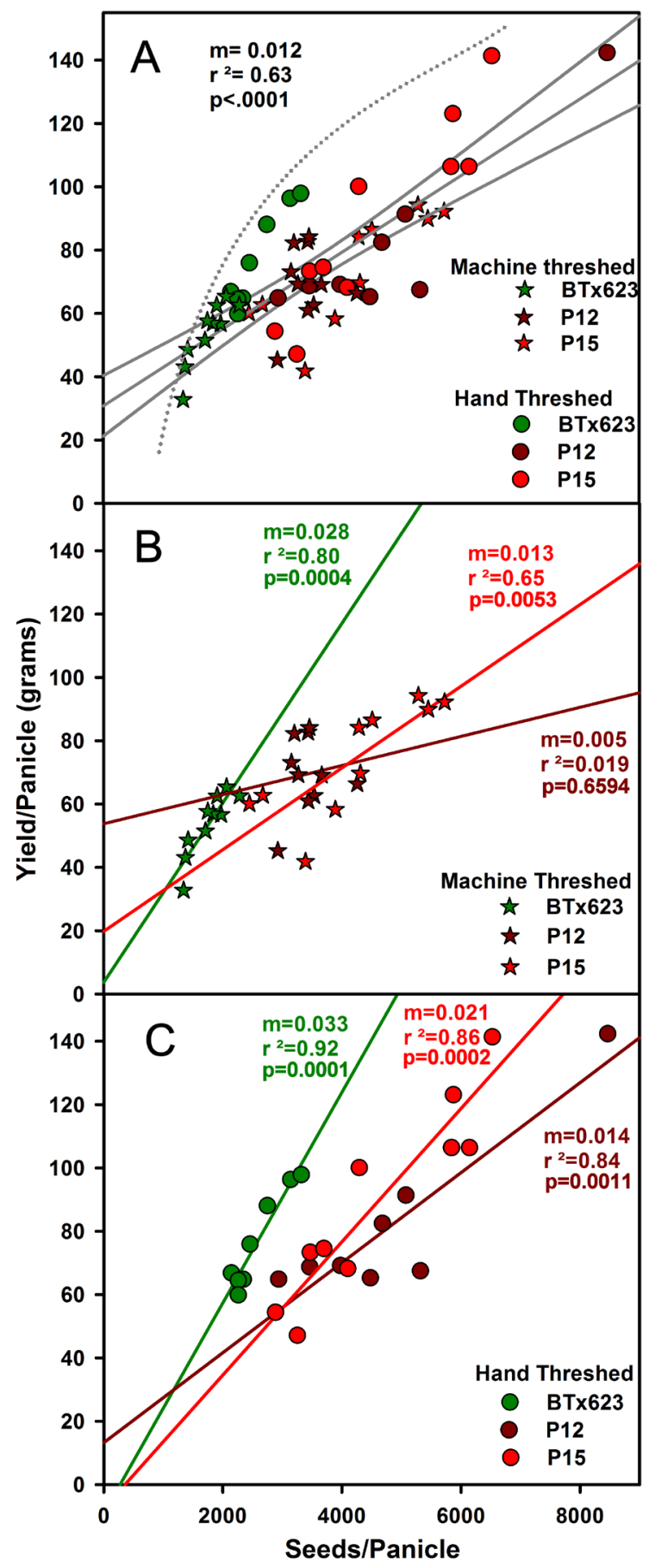

Figure 3. Regression analysis of individual panicle yield (mass) as a function of numbers of seeds per panicle. Top panel, (A) experiment-wide results; middle panel, (B) mechanically processed seeds; and bottom panel, (C) manually processed seeds.

Figure 3(A) (top panel) shows linear regression results illustrating the experiment wide linearity of response. It should be kept in mind that the numbers of seeds data in Figure 3 are derived from the number of seeds within a sample of known volume and scaled up to total seed volumes recovered from each panicle. The experiment wide correlation in Figure $3(\mathrm{~A})\left(\mathrm{r}^{2}=0.63\right)$ seems reasonable 
considering the wide range of seed sizes, and there was a significant correlation between seed number and grain yield $(\mathrm{p}<0.0001)$. The data also appeared to be a curvilinear response of maximal values with lower values beneath the response curve (dotted line in Figure 3(A)). This was not investigated further. Closer inspection of experiment wide data revealed that subtle differential interactions were occurring between both isolines and processing methods. A careful inspection reveals a remarkably linear response of the WT across both threshing methods as compared to the $m s d$ isolines, which exhibited differing levels of "scatter". This was later confirmed by regression analysis of BTx 623 for both processing methods.

In Figure 3(B) and Figure 3(C) results of linear regression for each isoline are displayed with each processing method in separate panes. In these cases, confidence intervals are not plotted in the interest of clarity. Moreover, plotting confidence intervals did not provide additional meaning to the results since the figures became quite cluttered and difficult to interpret. The slope, that is, the calculated average seed mass, of BTx623 (Figure 3(B) and Figure 3(C), green symbols and lines) were very nearly the same with both threshing methods. The very slight increase in average seed volume with manual processing is consistent with a slight increase as shown in Figure 2, derived from separate samples. Intercepts were -9.2 to $3.6 \mathrm{~g} /$ panicle, for the manual and machine processed seeds, respectively.

Calculated seed mass (slope) of the $m s d$ lines was considerably lower than that of the WT in both hand- and machine-threshed. However, the correlation was considerably lower than that of the BTx623 seeds, especially in the mechanically processed samples. Efficiency and reproducibility of seed recovery, as indicated by the correlation coefficient, was greater for manual threshing as compared to the mechanized. Moreover, the intercept of the regression functions of both msd lines were much closer to the origin in the manually processed samples, indicating that the method is much closer to the idealized case in which the intercept is at the co-ordinate origin.

\section{Discussion}

It is generally accepted that seed number is one of the most important factors determining grain yield in sorghum (e.g., 11). It has been reported that $m s d$ trait leads to $30 \%$ to $100 \%$ greater grain yields than that of the conventional line from which they were derived [10] [19]. However, there has been only a single study that attempted a preplanned systematic quantitative comparison of sorghum grain yield response to msd increased seed numbers in field grown plants [12]. In this study, they found unchanged harvest index and a statistically significant grain yield reduction in response to the msd phenotype. In contrast, the current study revealed a consistent trend towards greater grain yields as compared to BTx623 in both the mechanically processed and the manually processed seeds. When both msd lines were combined and compared to BTx623 yield, grain yield in- 
creases were statistically significant. Analysis of variance revealed a significant experiment wide msd grain yield increase. Taken together this suggests that there was a positive effect on msd yield. The question of a potential grain yield increase in response to the msd trait remains inconclusive and open. However, while the measured grain yield increase might be considered promising, it should be borne in mind that an examination of grain yield potential between the WT and the mutant was not the objective of this work. Our primary objective was to investigate and identify potential systematic errors that researchers might introduce to grain yield data of sorghums having widely differing seed sizes and using hand- and machine-threshing to harvest the grain. Even so, the results do point to the importance of larger uniformly sized seeds in existing harvesting equipment or perhaps the need to refine equipment to effectively handle smaller seeds or seeds of varying sizes.

The work described herein used individual plants as the replicable unit, the same approach used in the seminal work that compared only a few selected greenhouse grown plants [10]. Thus, the current work is subject to the same drawbacks as those from the original study [10]. Though considerably larger numbers of plants were examined in the current study, and although samples were taken from multiple plots in the field, the plots from which the samples were taken were grown for germplasm maintenance rather than for grain yield comparisons. Workers were asked to simply place bags over panicles for the purpose of investigating threshing and winnowing effectiveness. Hence, our grain yield results are from un-preplanned post hoc comparisons. For such reasons, even though samples were taken from field grown plants that were allowed to develop under agronomically relevant conditions, attempts to extrapolate grain yield results to that expected from the field scale might lack the predictive capability using more traditional formulaic statistical approaches such as multiyear studies using randomized plot design to address microenvironmental variability at the field-scale, or across the field.

We identified two potential systematic error sources that could be introduced with commonly used harvesting equipment. Vogel threshers use one or two rotary strippers and beaters in tandem with a winnowing box through which air is forced with a fan. With these threshers systematic errors associated with either mechanical threshing or with pneumatic cleaning can occur. Pneumatic cleaning errors can arise when seeds are small enough to pass through winnowing boxes with chaff and other trash. Mechanical errors can be introduced by not optimizing drum speeds for the materials resulting in either incompletely threshing seeds from the stalks (drum speed too low), or by shattering seeds with the drum rasp bars or vanes (drum speed too high).

With small seeds from the msd plants, manually threshing and cleaning resulted in higher recovery, which is consistent with our working hypothesis. The differences in the recovered seed masses as slope (slope had units of individual seed mass) from regression analysis was consistent with differential seed size se- 
lection by the two methods. This was confirmed by analysis of the seed size histograms. Mechanically threshed and cleaned seeds selected against a cohort of very small seeds. We attribute the loss of the very small msd seeds to loss in seed winnowing.

Problems with pneumatic separation of smaller seeds are well known. Smaller and irregularly shaped seeds have a lower cross-sectional density and higher drag coefficients, respectively, especially when irregularly shaped seeds are tumbling. This results in a lower terminal velocity or in the case of winnowing boxes increase in aerodynamic drag relative to momentum or inertial resistance to change in direction in airflow of rapidly changing direction.

The finding that hand threshing led to higher recovered seed yields in the larger seeded BTx623 sorghum was unexpected. On the contrary, we expected to see no difference in seeds recovered with hand threshing and cleaning as compared to mechanical threshing. Upon re-examination of a few samples left from threshing and on speaking with onsite agricultural technicians we were led to believe that larger sorghum seeds are often shattered by high threshing drum speeds, though this was never considered a problem. Seed shattering and subsequent loss was confirmed at least in part by regression analysis of recovered seed mass. Recall that the regression slope had units of individual seed mass. Individual seed mass (as slope) was very nearly the same in both the manually and mechanically processed WT seed; but recovery as total mass was higher in the manually processed samples. Thus, there was little differential discrimination in seed size between methods. The difference in recovered seeds must have resulted through a process other than pneumatic size selection. To further test the hypothesis that larger sorghum seeds tend to shatter on the Vogel thresher, samples of a different cultivar were examined on site. Between 3\% to 15\% ( $n=7$ samples) of total mass contained mechanically damaged seeds with very few small fragments. Taken together the evidence strongly suggests that seed fracturing could result in an underestimation of seed yield in large-seed sorghum.

It has been known at least as early as the 1960s that with larger seeds, higher threshing drum speeds, and lower seed moisture content, rotary drum threshers damage seeds. Wheat seed viability is reduced due to mechanical damage under such conditions [20]. Further, such seed damage has been described for other crops, including navybeans and soybean [21], and in relatively small seeded grain amaranth as well [22]. It is generally recommended that the lowest effective drum speed be used, since higher speeds invariably lead to such losses. Because this phenomenon is still being described and investigated and because sorghum breeding efforts using small plots and small plot threshers are experiencing renewed interest one wonders whether modern breeders are aware of the engineering problems associated with the small plot threshers and whether systematic errors associated with these are being addressed. In the present work we attribute the reduced seed recovery of BTx623 to seed shattering by mechanical threshing. 


\section{Conclusions}

In summary, an experiment-wide increase in seed yield of grain sorghum in response to the msd phenotype was observed. However, when the data were statistically analyzed these differences were found to be of limited significance. Nevertheless, no reduction in seed yield was found and the trend was for increased $m s d$ seed yield in every case. Nevertheless, these observations were well beyond the purview of this work and our results were inconclusive.

Two potential systematic error sources were identified for harvesting equipments that use mechanical threshing and pneumatic cleaning. Pneumatic cleaning errors can arise when seeds are small enough to pass through winnowing boxes. Mechanical errors were associated with seed shattering. The results underscored the importance of careful optimization of seed threshing and cleaning operations for plants with different seed sizes, shapes, and densities when attempting to make grain yield comparisons. For these reasons, the response of sorghum seed yield to the multiseed phenotype remains in question and unanswered.

\section{Acknowledgements}

We thank Dr. Lan Liu-Gitz for helpful discussions and suggestions through the course of this experiment and Messrs. Kyle Tengler and Ryan Mounce for their technical assistance. This research was supported in part by the Ogallala Aquifer Program, a consortium between USDA-Agricultural Research Service, Kansas State University, Texas A\&M AgriLife Research, Texas A\&M AgriLife Extension Service, Texas Tech University, and West Texas A\&M University.

\section{Conflicts of Interest}

The authors declare no conflicts of interest regarding the publication of this paper.

\section{References}

[1] Awika, J.M. (2011) Major Cereal Grains Production and Use around the World. In: Advances in Cereal Science: Implications to Food Processing and Health Promotion. ACS Symposium Series, American Chemical Society, Washington DC, 1-13. https://doi.org/10.1021/bk-2011-1089.ch001

[2] Taylor, J.R.N., Schober, T.J. and Bean, S.R. (2006) Novel Food and Non-Food Uses for Sorghum and Millets. Journal of Cereal Science, 44, 252-271. https://doi.org/10.1016/j.jcs.2006.06.009

[3] Ball, C.R. (1913) The Grain Sorghums: Immigrant Crops That Have Made Good. In: Yearbook of Agriculture, U.S. Department of Agriculture, Washington DC, 221-238. http://naldc.nal.usda.gov/naldc/download.xhtml?id=IND43747834\&content=PDF

[4] Martin, J.H. (1936) Sorghum Improvement. In: Yearbook of Agriculture, U.S. Department of Agriculture, Washington DC, 523-560.

[5] Mason, S.C., Kathol, D., Eskridge K.M. and Galusha T.D. (2008) Yield Increase Has Been More Rapid for Maize than for Grain Sorghum. Crop Science, 48, 1560-1568. https://doi.org/10.2135/cropsci2007.09.0529 
[6] Dahlberg, J., Berenji, J., Sikora, V. and Latkovic, D. (2011) Assessing Sorghum Sorghum bicolor (L.) Moench Germplasm for New Traits: Food, Fuels \& Unique Uses. Maydica, 56, 85-92. http://eprints.icrisat.ac.in/7455/1/Maydica_56_1750_85-92_2011.pdf

[7] Xin, Z., Wang, M.L., Burow, G. and Burke, J. (2009) An Induced Sorghum Mutant Population Suitable for Bioenergy Research. BioEnergy Research, 2, 10-16. https://doi.org/10.1007/s12155-008-9029-3

[8] Xin, Z., Gitz, D., Burow, G., Hayes, C. and Burke, J.J. (2015) Registration of Two Allelic Erect Leaf Mutants of Sorghum. Journal of Plant Registrations, 9, 254-257. https://doi.org/10.3198/jpr2014.09.0060crgs

[9] Gitz, D.C., Liu-Gitz, L., Xin, Z., Baker, J.T., Payton, P. and Lascano, R.J. (2017) Description of a Novel Allelic "Thick Leafed" Mutant of Sorghum. American Journal of Plant Sciences, 8, 2158-2742. https://doi.org/10.4236/ajps.2017.812200

[10] Burow, G., Xin, Z., Hayes, C. and Burke, J. (2014) Characterization of the Multiseed (msd1) Mutant of Sorghum for Increasing Grain Yield. Crop Science, 54, 2030-2037. https://doi.org/10.2135/cropsci2013.08.0566

[11] Jiao, Y., Lee, Y.K., Gladman, N., Chopra, R., Christensen, S.A., Regulski, M., Burow, G., Hayes, C., Burke, J., Ware, D. and Xin, Z. (2018) MSD1 Regulates Pedicellate Spikelet Fertility in Sorghum through the Jasmonic Acid Pathway. Nature Communications, 9, 822. https://doi.org/10.1038/s41467-018-03238-4

[12] Tolk, J.A. and Schwartz, R.C. (2017) Do More Seeds per Panicle Improve Grain Sorghum Yield? Crop Science, 57, 490-496. https://doi.org/10.2135/cropsci2016.04.0245

[13] Gitz, D.C., Baker, J.T., Payton, P., Xin, Z. and Lascano, R.J. (2018) Short Communication: Analysis of Grain Size Distribution through Image Analysis. American Journal of Plant Sciences, 9, 2339-2346. https://doi.org/10.4236/ajps.2018.912169

[14] Xin, Z., Wang, M.L., Barkley, N.A., Burow, G., Franks, C., Pederson, G. and Burke, J. (2008) Applying Genotyping (TILLING) and Phenotyping Analyses to Elucidate Gene Function in a Chemically Induced Sorghum Mutant Population. BMC Plant Biology, 8, 103-117. https://doi.org/10.1186/1471-2229-8-103

[15] Miller, F.R. (1977) Release of A and BTx622, 623, 624. Report of Technical Committee on Seed Release and Increase. College Station, TX.

[16] Stout, J.E. (2019) Plant Stress \& Water Conservation Unit Meteorological Tower, USDA Agricultural Research Service, Lubbock, TX.

http://www.lbk.ars.usda.gov/wewc/weather-pswc-data.aspx.html

[17] Gitz, D.C., Baker, J.T., Xin, Z., Lascano, R.J., Burke, J.J. and Duke, S.E. (2103) Research Note: Bird-Resistant Pollination Bags for Sorghum Breeding and Germplasm Maintenance. American Journal of Plant Sciences, 4, 571-574. https://doi.org/10.4236/ajps.2013.43074

[18] Vogel, O.A., Hermann, W. and Naffzinger, L.M. (1938) Two Improved Nursery Threshers. Agronomy Journal, 30, 537-542. https://doi.org/10.2134/agronj1938.00021962003000060012x

[19] Zhang, K., Zheng, G., Saul, K., Jiao, Y., Xin, Z. and Wang, D. (2017) Evaluation of the Multi-Seeded ( $m s d$ ) Mutant of Sorghum for Ethanol Production. Industrial Crops and Products, 97, 345-353. https://doi.org/10.1016/j.indcrop.2016.12.015

[20] Entz, M.H., Moes, J. and Stobbe, E.H. (1991) Seed Vigor of Katepwa Wheat: Interaction of Kernel Water Content and Threshing Cylinder Speed. Canadian Journal of Plant Science, 71, 619-627. https://doi.org/10.4141/cjps91-093 
[21] Singh, K.N. and Singh, B. (1981) Effect of Crop and Machine Parameters on Threshing Effectiveness and Seed Quality of Soybean. Journal of Agricultural Engineering Research, 26, 349-355. https://doi.org/10.1016/0021-8634(81)90076-7

[22] Krishnan, P., Evans, T.A. and Pill, W.G. (1994) Threshing Cylinder Speed Affects Germination of Amaranths cruentus L. Seeds. HortScience, 29, 652-654. 